\title{
A Concise Review on the Synthesis of Pyrazole Heterocycles
}

\author{
Ayaz Mahmood Dar* and Shamsuzzaman \\ Department of Chemistry, Aligarh Muslim University, Aligarh-202 002, India
}

\begin{abstract}
Study background: Pyrazole moiety, being called as pharmacophore, plays an important role in many biologically active compounds and therefore represents an interesting template for combinatorial as well as medicinal chemistry. In addition pyrazoles are also used extensively as useful synthons in organic synthesis. These derivatives have wide spread biological activities such as anticancer, analgesic, anti-inflammatory, antimicrobial, antiviral, anticonvulsant, antihistaminic and anti-HIV. The recent success of pyrazole COX-2 inhibitor has further highlighted the importance of these heterocycles in medicinal chemistry.

Methodology: The steps included condensation followed by cyclization or MCR, either in a step-wise manner or in one pot has been achieved successfully to obtain this class of heterocycles under different conditions. Phosphorus oxychloride $\left(\mathrm{POCl}_{3}\right)$, dimethyl formamide, acetamide and hydrazine are the most common reagents used for the synthesis of pyrazole appended heterocyclic skeletons.

Results: The reaction schemes resulted in the synthesis of heterocyclic appended pyrazoles in potential yields under either simple reaction conditions or microwave irradiation.

Conclusion: These protocols provide convenient strategies to annelate different heterocyclic nuclei with widespread bioactive pyrazoles thereby extending the categories of heterocyclic systems. These strategies also provide valuable information for the further design of more active biological agents through various modifications and derivatizations.
\end{abstract}

Keywords: Pyrazole; Dimethyl formamide; Phosphorus oxychloride; Hydrazine

\section{Introduction}

Polyfunctionalized heterocyclic compounds play important roles in the drug discovery process and analysis of drugs in late development or in the market shows that $68 \%$ of them are heterocycles. Hence it is not surprising that research on the synthesis of polyfunctionalized heterocyclic compounds has received significant attention in the recent years. The pyrazole system (1) consists of a doubly unsaturated five membered ring with two adjacent nitrogen atoms. Knorr [1,2] first synthesized compounds containing this system in 1883 by the reaction of ethyl acetoacetate with phenyl hydrazine, which yielded 1-phenyl-3methyl-5-pyrazolone (2). Knorr [3] introduced the name pyrazole for these compounds to denote that the nucleus was derived from pyrrole by the replacement of a carbon by nitrogen. They synthesized many members of this class and systematically investigated their properties.<smiles>c1cn[nH]c1</smiles>

(1)<smiles>CC1=NN(c2ccccc2)C(=O)C1</smiles>

(2)
Literature survey has revealed that till 1930s very little had been done for the synthesis of steroidal pyrazole derivatives. Probably the first steroidal pyrazole was reported in 1938 by Ruzicka et al. [4] and only a single derivative; cholest-4-eno [3,2-c] pyrazole-5-carboxylic acid (3) was mentioned.

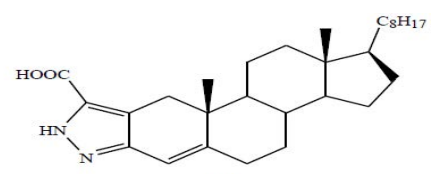

(3)
After a considerable span of time, much attention has been paid by a number of organic chemists towards the synthesis of several steroidal pyrazoles. The effect on different biological activities produced by the fusion of a pyrazole ring to the steroid nucleus has prompted us to investigate such type of compounds. The compounds containing pyrazole ring system can be synthesized by different routes and here we have summarized only important examples, as below.

\section{Reaction Protocols}

Kira et al. [5] reported that treatment of acetophenone phenylhydrazone (4a-d) with two moles of DMF- $\mathrm{POCl}_{3}$ in DMF at $70-80^{\circ} \mathrm{C}$ for $6 \mathrm{~h}$ gave immonium perchlorate. Alkaline hydrolysis of immonium perchlorate afforded 1,3-diarylpyrazole-4-carboxaldehyde (5a-d).

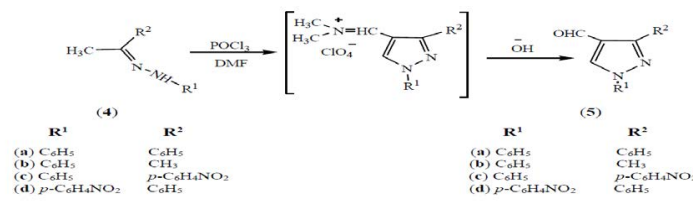

*Corresponding author: Ayaz Mahmood Dar, Senior Researcher, Department of Chemistry, Aligarh Muslim University, Aligarh-202 002, India, Tel: +919286990247; E-mail: ayazchem09@gmail.com, manzayaz.bh@amu.ac.in

Received August 16, 2015; Accepted September 14, 2015; Published September 18,2015

Citation: Dar AM, Shamsuzzaman (2015) A Concise Review on the Synthesis of Pyrazole Heterocycles. J Nucl Med Radiat Ther 5: 250. doi:10.4172/21559619.1000250

Copyright: (C) 2015 Dar AM, et al. This is an open-access article distributed unde the terms of the Creative Commons Attribution License, which permits unrestricted use, distribution, and reproduction in any medium, provided the original author and source are credited. 
Citation: Dar AM, Shamsuzzaman (2015) A Concise Review on the Synthesis of Pyrazole Heterocycles. J Nucl Med Radiat Ther 5: 250. doi:10.4172/2155-9619.1000250

Kira et al. [6] synthesized 3-substituted pyrazole-4-carboxaldehyde (7a-f) by the reaction of semicarbazones (6a-f) with two moles of DMF$\mathrm{POCl}_{3}$ in DMF.

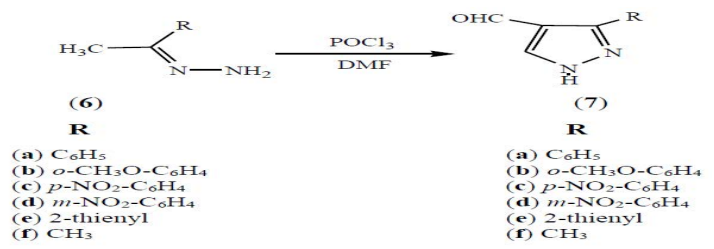

Bavatenko et al. [7] reported substituted pyrazoles (9a-d) by cyclizing aryl hydrazones (8a-d) under Vilsmeier conditions.

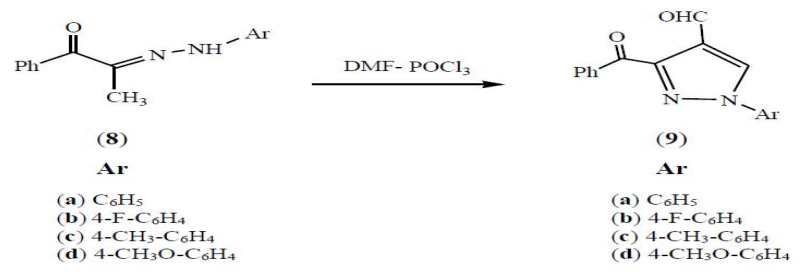

3,5-Disubstituted pyrazoles (11a-d) were obtained by the reaction of gem-dichlorocyclopropylacetates $(\mathbf{1 0 a}, \mathbf{b})$ with 4 equivalents of hydrazine or phenyl hydrazine at room temperature while metacyclophane (13a) and its isomer (13b) were obtained from 1-acetoxy-2,2-dichlorobicyclo [10.1.0] tridecane (12) with hydrazine under same condition [8].

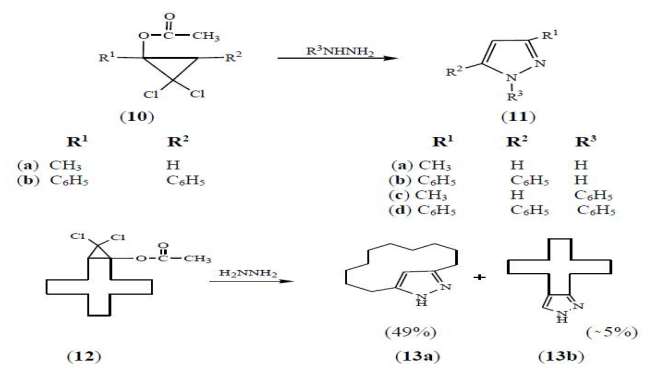

Pawar and Borse [9] reported 4-n-alkyl substituted pyrazoles (15af) from phenyl hydrazones (14a-d), semicarbazone (14e) and azine of 2-n-acyl-5-chlorophenol (14f) by monoformylation and cyclization by using one mole of the Vilsmeier-Haack reagent (DMF-POCl ${ }_{3}$ ).

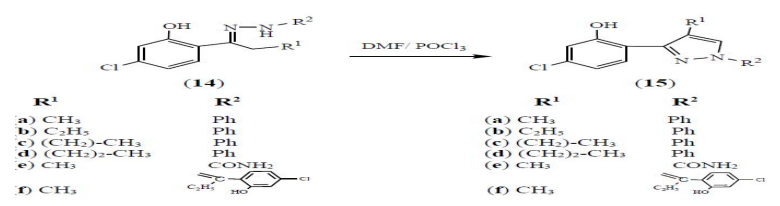

Sridhar [10] reported pyrazole-4-carboxaldehyde (17a-h) by the reaction of hydrazones of aliphatic and aromatic methylketones (16a-h) with Vilsmeier reagent. They also studied the reactivity of hydrazones of $\beta$-ketoesters towards Vilsmeier reagent, both by conventional and microwave methods.

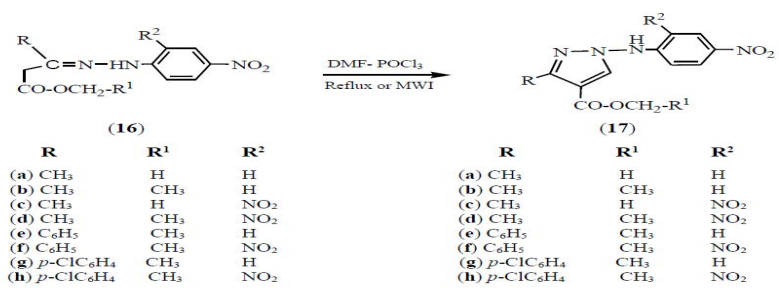

Borrell et al. [11] synthesized pyrazole library by using Merrifield resin as a solid-phase support to a hydroxyacetophenone (18), VilsmeierHaack formylation on methyl group and cyclization with substituted hydrazine to afford 4-hydroxybenzoyl-1-substituted pyrazoles (20a-e).



Dhar and Bhat [12] reported the synthesis of 3,5-diphenyl-1Hpyrazole (24) from chalcone (21) by the action of hydrazine hydrate on chalcone-epoxide (22) followed by simultaneous dehydration in presence of catalytic amount of concentrated sulphuric acid in acetic acid.

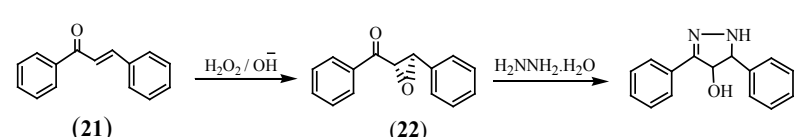

(21)<smiles></smiles>

(22)

(23)<smiles>[141In]</smiles>

Kidwai et al. [13] used microwave irradiation and synthesized 4-methyl-2-[3'-substituted-phenyl-4'-formylpyrozolyl] quinoline (26a-d) by the reaction of hydrazones of methylquinoline (25a-d) with $\mathrm{DMF}$ and $\mathrm{POCl}_{3}$ under microwave irradiation of 3-4 min.



3-Aryl-4-formyl-1-[3(2-chlorophenyl)-1,8-naphthyridin-2-yl] pyrazoles (28a-d) were obtained when hydrazones (27a-d) were subjected to microwave irradiation [14] in the presence of VilsmeierHaack reagent.

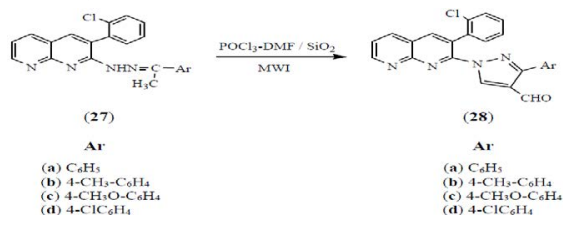

Selvi and Perumul [15] synthesized 4-ethoxy-4H-benzopyrano [4,3-c]pyrazoles (30a-f) from $o$-hydroxyacetophenone-2,4dinitrophenylhydrazone (29a-f) under Vilsmeier conditions. 
Citation: Dar AM, Shamsuzzaman (2015) A Concise Review on the Synthesis of Pyrazole Heterocycles. J Nucl Med Radiat Ther 5: 250. doi:10.4172/2155-9619.1000250

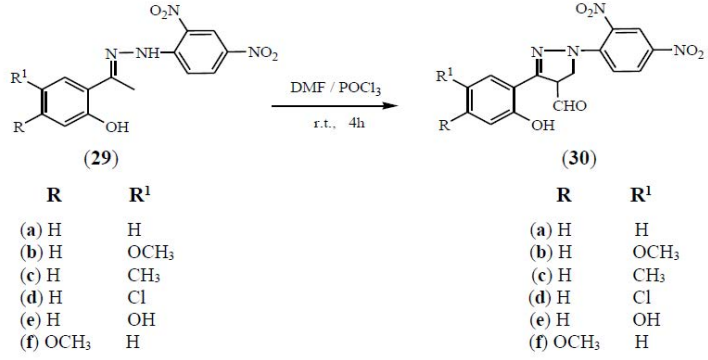

Singh et al. [16] reported the synthesis of pyrazolo [3,2-c]cholest4-ene (32) and [1'H]-5'-(methylthio) pyrazolo [3,2-c]cholest-4-ene (34) from 2-ethoxymethylene-4-cholest-4-en-3-one (31) and bis (methylthio) methylene cholest-4-en-3-one (33), respectively by the action of hydrazine hydrate in ethanol under reflux.



Clinton et al. [17] reported that the treatment of $17 \alpha$-methylandrostan-17 $\beta$-ol-3-one (35) with ethylformate and sodium methoxide gave 2 -hydroxymethylene derivative (36) which on condensation with hydrazine gave $17 \beta$-hydroxy-17 $\alpha$-methylandrostano [3,2-c] pyrazole (37). Similar treatment of 2-hydroxymethylene$17 \alpha$-androst-4-en-17 $\beta$-ol-3-one (38) furnished $17 \beta$-hydroxy- $17 \alpha$ methylandrost-4-eno $[3,2-c]$ pyrazole (39).

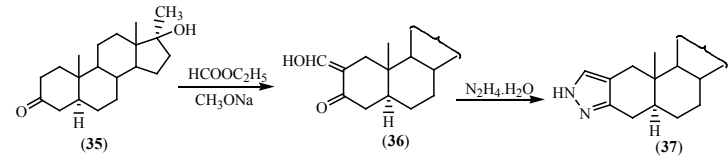<smiles>CC12CC(=CO)C(=O)C=C1CCC1C2CCC2(C)C1CC[C@]2(C)O</smiles>

(38)



(39)
Berbalk et al. [18] reported that the epoxyandrostane (40a-c) underwent formolysis to give phenyl acetylandrostane (41a-c) which on further cyclocondensation with hydrazine afforded steroidal pyrazoles $(42 a-c)$.

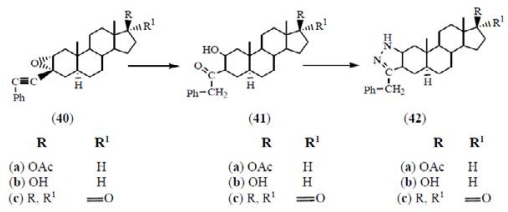

Bonn and Dodson [19] carried out the hydrazine reduction of $16 \alpha, 17$-epoxy-pregnenolone (43) to obtain $3 \beta$-hydroxyandrost-5-eno $[16,17-c]-5-m e t h y l p y r a z o l e ~(44)$ along with the two isomeric allylic alcohols, 5,17 [20]-(cis)-pregnadiene-3 $\beta, 16 \alpha$-diol (45a) and 5,17 [20]-(trans)-pregnadiene-3 $\beta, 16 \alpha$-diol (45b).

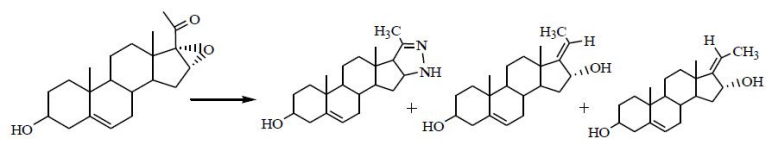

(43) (44) (45a) (45b)

Laitonjan et al. [20] synthesized substituted steroidal [3,2-c] pyrazoles $(47 \mathbf{a}, \mathbf{b})$ by the reaction of 2-ethoxymethylene-4-cholestan-3one (46a) and 2-bis (methylthio) methylene cholest-4-en-3-one (46b) with hydrazine hydrate and refluxed for $3 \mathrm{~h}$.



Peseke et al. [21] reported that the treatment of $3 \beta$-acetoxy-16-[bis (methylthio) methylene]-5-androst-5-en-17-one (48) with hydrazine hydrate and methylhydrazine afforded the 5-methylthio-pyrazolo $\left[4^{\prime}, 3^{\prime}: 16,17\right]$ androst-5-en-3 $\beta$-ols $(49 \mathbf{a}, \mathbf{b})$.



(48)



$\mathbf{R}$

(a) $\mathrm{H}$

(b) $\mathrm{CH}$

Shamsuzzaman et al. [22] reported that the treatment of $5 \alpha$-cholestan-6-one tosylhydrazones (50a-c) with Vilsmeier reagent gave $5^{\prime}$-formyl- $5 \alpha$-cholestan $[6,7-c]$ pyrazole derivatives (51a-c) in 60 $65 \%$ yields.

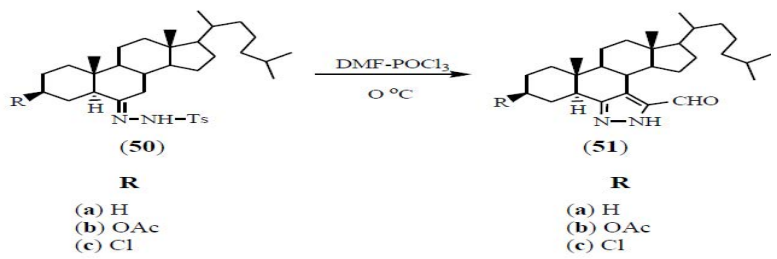

Sidhaye et al. [23] reported that nicotinoyl chloride (52) reacted with hydrazine and gave nicotinohydrazide (53). The compound (53) on reaction with acid derivatives yielded (3,5-dimethyl-1H-pyrazol-1yl)(pyridine-3-yl) methanone (54), 3-methyl-1-nicotinoyl-1H-pyrazol5(4H)-one (55), 3-amino-1-nicotinoyl-1H-pyrazol-5(4H)-one (56) in good amounts.




Citation: Dar AM, Shamsuzzaman (2015) A Concise Review on the Synthesis of Pyrazole Heterocycles. J Nucl Med Radiat Ther 5: 250. doi:10.4172/2155-9619.1000250

Isloor et al. [24] reported the reaction of substituted hydrazines (57a-g) with ethyl acetoacetate in absolute alcohol which provided the corresponding substituted pyrazolones $(\mathbf{5 8 a}-\mathbf{g})$ in good yields.

\begin{tabular}{|c|c|}
\hline (57) & (58) \\
\hline $\mathbf{A r}$ & $\mathbf{A r}$ \\
\hline $\begin{array}{l}\text { (a) } \mathrm{C}_{6} \mathrm{H}_{5} \\
\text { (b) } 2,4 \text {-DNP } \\
\text { (c) 4-Chlorophenyl } \\
\text { (d) } 4-\mathrm{OCH}_{3}-\mathrm{C}_{6} \mathrm{H}_{4} \\
\text { (e) } \mathrm{Biphenyl} \\
\text { (f) } 2,4 \text {-Dichlorophenyl } \\
\text { (g) } 4-\mathrm{SCH}_{3}-\mathrm{C}_{6} \mathrm{H}_{4}\end{array}$ & $\begin{array}{l}\text { (a) } \mathrm{C}_{6} \mathrm{H}_{5} \\
\text { (b) } 2,4-\mathrm{DNP} \\
\text { (c) 4-Chlorophenyl } \\
\text { (d) 4-OCH}-\mathrm{C}_{6} \mathrm{H}_{4} \\
\text { (e) Biphenyl } \\
\text { (f) } 2,4-\mathrm{Dich} \text { lorophenyl } \\
\text { (g) } 4-\mathrm{SCH}_{3}-\mathrm{C}_{6} \mathrm{H}_{4}\end{array}$ \\
\hline
\end{tabular}

Mariappan et al. [25] reported that the reaction of ethyl acetoacetate with hydrazine hydrate in absolute alcohol yielded pyrazolone (59). The pyrazolone (59) upon reaction with different substituted aromatic aldehydes in presence of alcoholic sodium hydroxide yielded corresponding substituted pyrazolones $(60 \mathbf{a}-\mathbf{h})$.

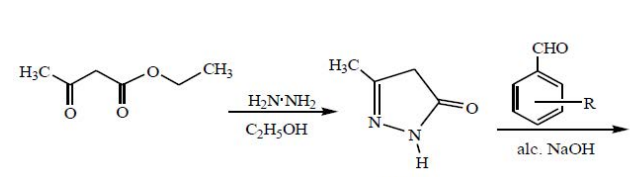

(59)

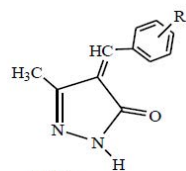

$(60)$ (a) $\mathrm{N}\left(\mathrm{CH}_{3}\right)_{2} \quad$ (e) $3-\mathrm{Cl}$ (b) $\mathrm{Ph}-\mathrm{CH}=\mathrm{CH}$ (f) $4-\mathrm{OM}$

(c) $\mathrm{OCH}_{3}$, 3) (g) 3 -OMe

$\begin{array}{ll}\text { (d) } 3-\mathrm{NO}_{2} & \text { (h) } \mathrm{OH}\end{array}$

Rao and Chunduru [26] reported the one pot synthesis of 4-arylidene-3-methyl-1-[4-(2-oxo-2H-chromen-3-yl) thiazol-2yl]-1H-pyrazol-5(4H)-ones (63a-d) by reacting 3-(2-bromoacetyl) coumarin derivatives (61a-d), thiosemicarbazide, ethyl acetoacetate and substituted aryl aldehydes (62a-d) in presence of sodium acetate in acetic acid.

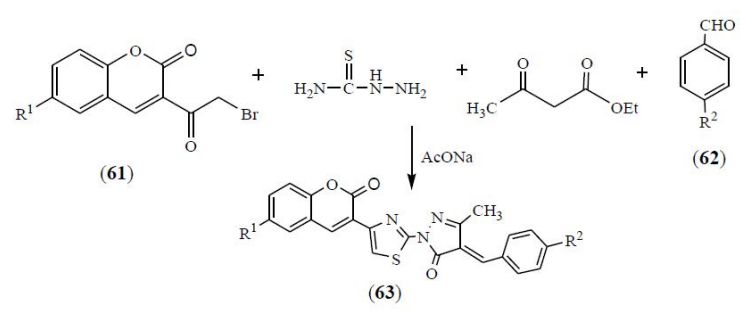

\begin{tabular}{|c|c|c|c|}
\hline (61) & (62) & \multicolumn{2}{|c|}{ (63) } \\
\hline $\mathbf{R}^{1}$ & $\mathbf{R}^{2}$ & $\mathbf{R}^{1}$ & $\mathbf{R}^{2}$ \\
\hline $\begin{array}{l}\text { (a) } \mathrm{H} \\
\text { (b) } \mathrm{Br} \\
\text { (c) } \mathrm{NO}_{2} \\
\text { (d) } \mathrm{OCH}_{3}\end{array}$ & $\begin{array}{l}\text { (a) } \mathrm{NH}_{2} \\
\text { (b) } \mathrm{NMe}_{2} \\
\text { (c) } \mathrm{NO}_{2} \\
\text { (d) } \mathrm{NHMe}^{2}\end{array}$ & $\begin{array}{l}\text { (a) } \mathrm{H} \\
\text { (b) } \mathrm{Br} \\
\text { (c) } \mathrm{NO}_{2} \\
\text { (d) } \mathrm{OCH}_{3}\end{array}$ & $\begin{array}{l}\mathrm{NH}_{2} \\
\mathrm{NMe}_{2} \\
\mathrm{NO}_{2} \\
\mathrm{NHMe}\end{array}$ \\
\hline
\end{tabular}

Ayaz M Dar and Shamsuzzaman [27] also reported the expeditious and convenient synthesis of new 5a-cholestano [6,7-c]-5'-methyl1 '-carbothioic acid amide pyrazoles (65d-f) based on the reaction of 5a-cholestan-6-one thiosemicarbazones (64a-c) with modified Vilsmeier-Haack reagent $\left(\mathrm{H}_{3} \mathrm{C}-\mathrm{CO}-\mathrm{NH}_{2} / \mathrm{POCl}_{3}\right)$.

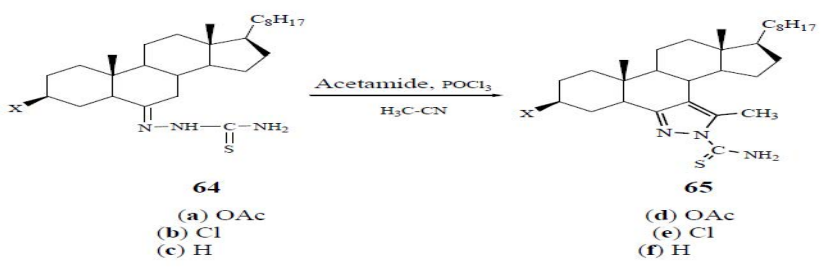

\section{Conclusion}

In this article we have mentioned the different routes for the synthesis of pyrazole derivatives. The steps included condensation followed by cyclization or multi-component reaction (MCR), either in a step-wise manner or in one pot; either simple refluxing/stirring or microwave irradiation, has been achieved successfully to obtain the aforementioned class of heterocycles under different conditions. Most of the preparative methods included phosphorus oxychloride $\left(\mathrm{POCl}_{3}\right)$, dimethyl formamide, acetamide and hydrazine as common reagents for the synthesis of pyrazole appended heterocyclic skeletons. Also many series of substituted pyrazole fused six membered heterocycles possessing $\mathrm{N}-, \mathrm{S}$ and $\mathrm{O}$ - have been constructed in potential yields. Hence these protocols provide convenient strategies to annelate different heterocyclic nuclei with widespread bioactive pyrazoles thereby extending the categories of heterocyclic systems.

\section{Acknowledgement}

Author (AMD) thanks Dr. Shamsuzzaman, Professor of Chemistry, AMU Aligarh, for useful discussions during the literature survey and University Grants Commission for providing research fellowship for successful completion of this work.

\section{References}

1. Knorr L (1883) German Patent 26: 429.

2. Knorr L (1883) Ber 16: 2597.

3. Knorr L, Blank A (1885) Ber 18: 311.

4. Ruzicka L, Platter PA (1938) Helv Chim Acta 21: 1717.

5. Kira MA, Raeman MOA, Gadalla KZ (1969) Tetrahedron Lett 2: 109

6. Kira MA, Gnein MNA, Korkor MI (1970) J Heterocycl Chem 7: 25.

7. Brantenko MK, Chornous VA, Vovk MV (2001) Chem Heterocycl Comp 37: 467

8. Parham WE, Dooley JE (1967) J Am Chem Soc 15: 985.

9. Pawar RA, Borse AP (1989) J Indian Chem Soc 66: 203.

10. Sridhar R, Perumal PT (2003) Synth Commun 33: 1483.

11. Borrell JI, Schuler E, Teixidó J, Michelotti EL (2004) Design and synthesis of two pyrazole libraries based on o-hydroxyacetophenones. Mol Divers 8: 147157.

12. Bhat BA, Dhar KL, Puri SC, Qurishi MA, Khajuria A, et al. (2005) Isolation, characterization and biological evaluation of datura lactones as potential immunomodulators. Bioorg Med Chem 13: 6672-6677.

13. Kidwai M, Goel Y, Kumar R (1998) Indian J Chem 37B: 174.

14. Mogialih K, Reddy SC (1998) Indian J Chem 43B: 2010.

15. Selvi S, Perumal PT (2000) Indian J Chem 39B: 163.

16. Singh RKT, Singh LW (1999) Indian J Chem 38B: 847.

17. Manson AJ, Stonner FW, Neumann HC, Christiansen RG, Clarke RL, et al (1963) Steroidal Heterocycles. VII. Androstano(2,3-D)Isoxazoles And Related Compounds. J Med Chem 6: 1-9. 
Citation: Dar AM, Shamsuzzaman (2015) A Concise Review on the Synthesis of Pyrazole Heterocycles. J Nucl Med Radiat Ther 5: 250. doi:10.4172/2155-9619.1000250

Page 5 of 5

18. Berbalk H, Eichinger K, Schuster R (1982) Arch Pharm 315: 79.

19. Benn WR, Dodson RM (1964) J Org Chem 29: 1142.

20. Laitonjam WS, Rajkumar TS, Chingakham BS (2002) Synthesis of some Aand D-ring fused steroidal pyrazoles, isoxazoles and pyrimidines. Steroids 67 203-209.

21. Rivera DG, Pesek K, Jommaran T, Montero A, Molina R, Coll F (2003) Molecules 8: 444.

22. Shamsuzzaman, Khan MS, Tabassum Z, Alam M (2009) Indian J Chem 48B 1183.
23. Sidhaye RV, Dhanawade AE, Manasa K, Aishwarya G (2011) Curr Pharm Res 1: 135.

24. Vijesh AM, Isloor AM, Peethambar SK, Shivananda KN, Arulmoli T, et al (2011) Hantzsch reaction: synthesis and characterization of some new ,4-dihydropyridine derivatives as potent antimicrobial and antioxidant agents. Eur J Med Chem 46: 5591-5597.

25. Marriapan G, Saha BP, Sutharson L, Haider A (2010) Indian J Chem 49B: 1671

26. Chunduru VSR, Rao VR (2010) J Sulfur Chem 31: 545

27. Dar AM, Shamsuzzaman (2014) Eur Chem Bull 3: 1104-1106. 